\title{
An analysis of the Greek Special Program for roof-mounted photovoltaic systems
}

\author{
K. Gkarakis \\ RES Lab, Department of Energy Engineering, \\ Technological Educational Institute (TEI) of Athens, Greece
}

\begin{abstract}
Greece ranks 5th worldwide with regard to per capita installed photovoltaic (PV) capacity. $€ 4.5$ billion was invested in PV in Greece during the last 5 years. In 2014, $\mathrm{PV}$ is expected to cover $7 \%$ of electricity demand. For a small country in an unprecedented financial crisis, this performance is indeed amazing. There is a very good reason for this: a brave support mechanism. This has skyrocketed the market, especially during the period 2011-2013, and reached a cumulative installed PV capacity of $2.6 \mathrm{GWp}$ in June of 2014 . However, this very mechanism has also overheated the market. High feed-in-tariffs and dramatic decreases of PV costs, since 2011, have led to an installation boom that the electricity market cannot sustain anymore. The Greek State took measures by reducing the fed-in-tariffs in existing and new installations, with result to bring new installations market into a halt. Today, the installed capacity of solar roofs is approximately $373 \mathrm{MW}$ numbering 41.217 installations. The purpose of the present paper is: (i) to analyse the current market situation of the roof mounted photovoltaic systems in Greece, focusing also in environmental benefits and attempts to segment the development of this market based on the legislation and the incentives, (ii) investigates the existing policy, as well as the crucial barriers for the continuation of the development of solar roofs and (iii) records the market proposals for the future. Keywords: Greek Special Program for photovoltaics in buildings, solar roofs, development of the market, energy policy, overheated market.
\end{abstract}

\section{Introduction}

During the last six years there was a continuous increase of interest in exploitation of solar energy through photovoltaics (PV) in Greece. This was a combined effect of (i) the favorable legal and support mechanism, (ii) the high solar energy potential of the country and (iii) the rising environmental awareness. 
In 2014 PV's are expected to cover 7\% of the electricity demand in Greece through an installed capacity of $2.6 \mathrm{GWp}$ in June of 2014 [1].

In 2013 the installations were more than $1 \mathrm{GW}$ while in 2014 the country experienced a dramatic fall, installing a miniscule of only 5.5 MW. According to the latest statistics published by Electricity Market Operator (EMO) this month, the country installed: $1 \mathrm{MW}$ of rooftop projects (Special Program - each installation consists of less than $10 \mathrm{kWp}$ ) and $3 \mathrm{MW}$ of ground-mounted PV projects (each larger than $10 \mathrm{kWp}$ capacity) in the period between January and October 2014 [2].

A percentage of $14.5 \%$ of the total installed capacity is installed in buildings and domestic sector based on a Special Program of the Development [1] (373 MW with 41.217 installations on June 2014). The PV capacity of this program is limited to $10 \mathrm{kWp}$ per installation for systems installed in the mainland (interconnected electrical system) and to $5 \mathrm{kWp}$ for non-interconnected islands.

The market has been overheated due to high feed-in-tariffs (FiTs) and dramatic decreases of PV costs since 2011 which have led to an installation boom that the Electricity Market cannot sustain anymore. The EMO cannot raise the necessary funds for compensating the PV installations, so in the last years the Greek State has published several laws and ministerial decrees which have reduced the FiTs in existing and new installations. After these changes in legislation and mainly in incentives, the market has frozen and the new installed capacity has been dramatically reduced. Finally, the PV market, especially in buildings and domestic installations, is stagnant and the estimations from EMO are pessimistic for the next two years [2].

\section{Legal framework}

The Special Program was launched on the 1st of July 2009 for both mainland and interconnected islands. For the non-Interconnected islands, after the available capacity on the area of each island was examined, the implementation of the Special Program began on the 10th of January 2011, by decision 1251/2010 of the Regulatory Authority for Energy (RAE).

The basic legislative document for the Special Program is the Joint Ministerial Decree 1079/04.06.2009. The modifications are based on the following joint ministerial decrees (JMD) and law (L):

- JMD $1557 / 22.09 .2010$

- JMD 2317/10.08.2012

- JMD 1103/02.05.2013

- $\quad$ L 4254/2014/07.04.2014

\subsection{Basic characteristics of the Special Program}

The Special Program refers to the whole territory. The maximum capacity per installation is defined to $10 \mathrm{kWp}$ for the mainland, the interconnected islands with the mainland system, as well as for Crete and to $5 \mathrm{kWp}$ for the rest of the NonInterconnected islands. 
This Special Program offers the capability to install stable building integrated photovoltaic systems on buildings which are used as residence or very small businesses mainly on roof-top structures and roofs of legally existed buildings, on shelters, facades and auxiliary areas (warehouses, parking spaces etc.) It is obvious that the auxiliary areas must be located within the same field with the main building; otherwise they cannot be characterized as such. It is clarified that any area or combination of areas mentioned above can be selected for the installation of the PV system. In any case, the installation of a PV system on the ground is not allowed within the framework of the Special Program (e.g. in a vacant area of a field) [3].

Integration into the PV systems program can be requested by natural persons non self-employed, natural or legal entities that are self-employed who run very small businesses, Public Legal Entities as well as non-profit Private Legal Entities who have full ownership or usufruct or bare ownership under the necessary condition that they have the usufructuary's consent for the area in which the PV system will be installed and that they use the building as residence or for their activities [3].

The right to install a PV system in a building which belongs to a Public Legal Entity, the use of which is undertaken by a building manager (e.g. school committee), is granted to the manager after the building owner's consent. In cases of PV system installation on public or commonly used areas, only one PV system is allowed to be installed. In this case, the right for integration into the Program is provided only to the owners of the horizontal properties represented by the manager or one of the owners of the horizontal properties after concession for use of the public or common area by the rest of the co-owners. Prerequisite is the consent of all building co-owners with the responsibility of the interested parties.

The main condition for the PV installation is the existence of an active power supply in the building of installation under the name of the PV system owner (physical/legal person).

Additionally, when the building on which the PV system is installed is used as a residence, then as prerequisite is considered the fact that part of the thermic needs in hot water will be covered by the use of renewable energy sources (such as solar water heaters, solar thermal systems) according to the Joint Ministerial Decision. Also, the PV system installation project should not be integrated into another funding program.

The metering of the energy generated by the PV system is realized simultaneously with the consumed energy metering, that is, the same cycle of metering is applied with the one realized for the consumed energy. However, the payment of the produced energy is made in the actual bill (not in the estimated bill). If, for any reason, the metering indications are not taken in the scheduled metering date, the netting will be made when the next regular metering will take place. The credit from the energy generated by the PV system is displayed on the electricity bill of the PV system owner. Substantially, the electricity bill is considered as purchase invoice. This amount of credit is offset with the obligations deriving from the Power Supply Agreement. In case which the total electricity bill is a credit bill then the amount is credited to the bank account of the PV system 
owner on the expiration date of the electricity bill. The income from the energy production is tax-free.

The Netting Agreement signed between the Supplier (mainly Public Power Corporation SA (PPC) - ex public company) and the owner of the PV system is applied for duration of 25 years, starting from the date of the PV system connection activation. The duration of the Program is until the end of 2019.
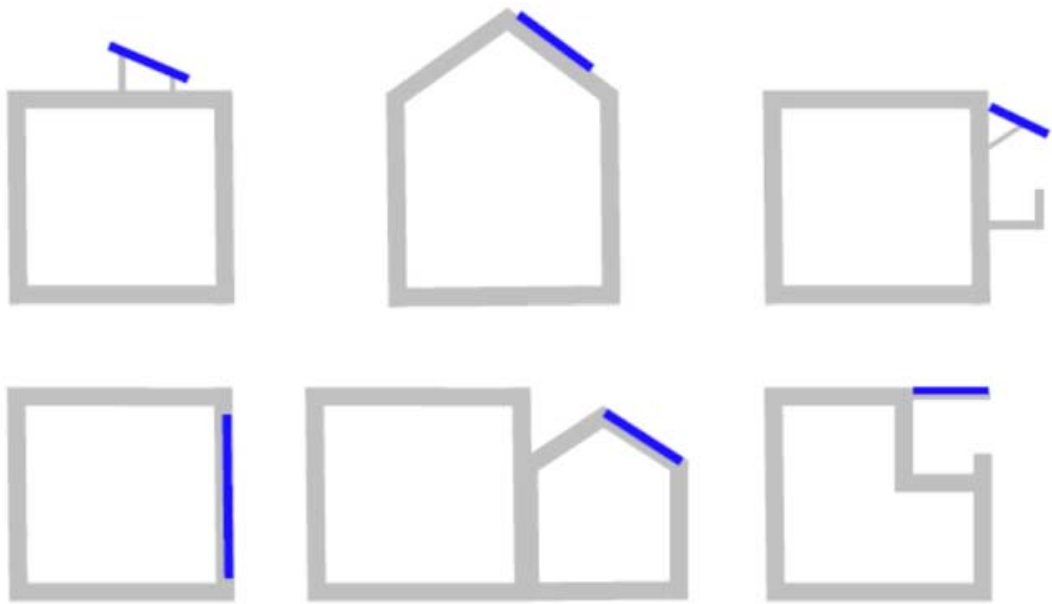

Figure 1: Possible areas where PV of the Special Program is allowed to be installed.
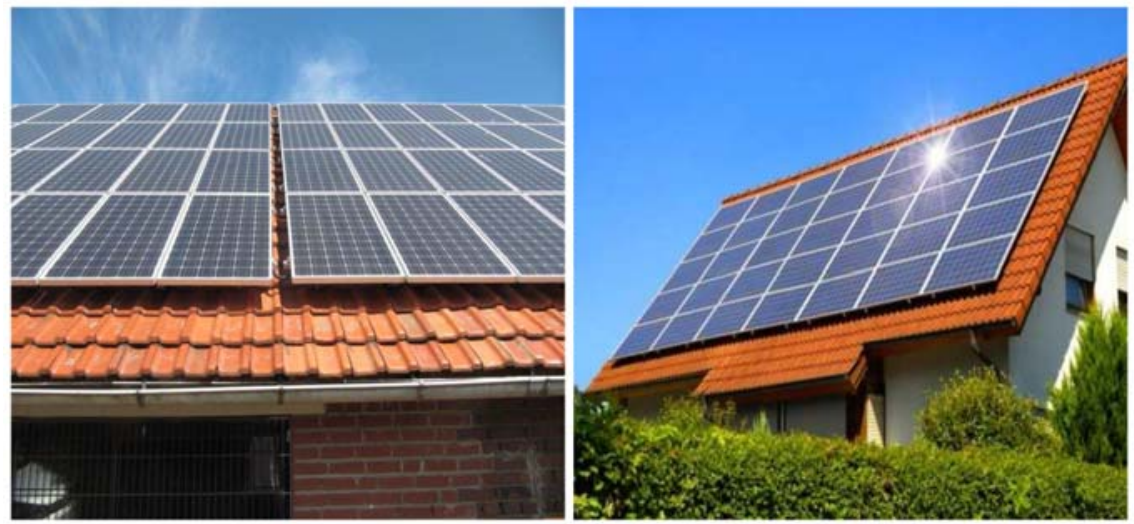

Figure 2: Indicatives types of PV installations of the Special Program. 

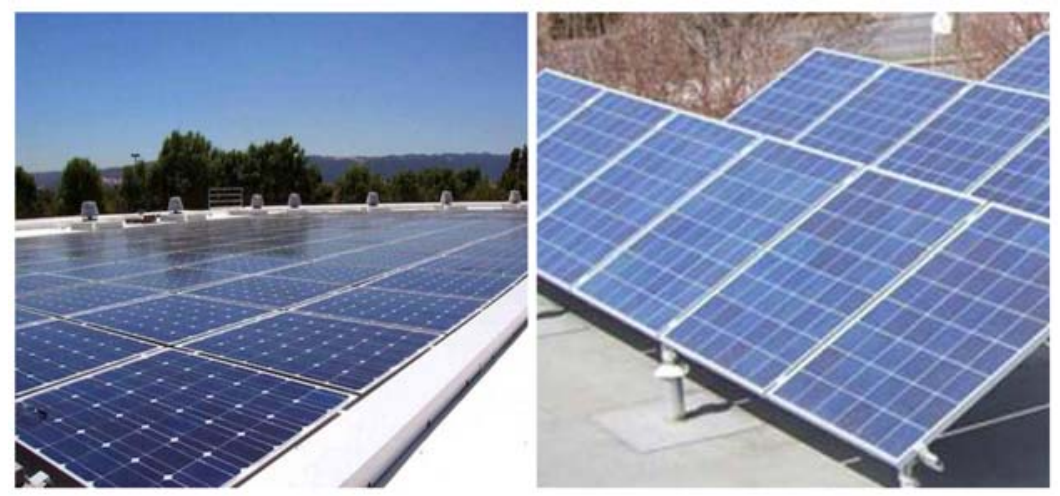

Figure 3: Indicatives types of PV installations of the Special Program.

\subsection{Feed in tariff - initial status and changes}

The price of the energy produced by the PV system was initially defined at 550 Euro/MWh (04.06.2009) until the end of 2011 furthermore an annual reduction of $5 \%$ for the period of 2012-2019 was applied. The price mentioned in the Netting Agreement is annually adjusted per $25 \%$ of the consumer price index of the previous year. If the price derived from the above adjustment is lower than the mean Limit Value of the System as formed during the previous year, increased by $40 \%$, the pricing will be made based on the mean Limit Value of the System of the previous year, increased by the above relevant coefficient. If the PV system connection activation will be made after the passage of six months from the conclusion of the Netting Agreement, then, the price that corresponds to the year in which the activation of the PV system connection takes place.

Due to offering high feed-in-tariffs (FiTs) for PV, the market skyrocketed especially during the period middle of 2011 - middle of 2013 and the installed capacity has reached extremely high rates.

Banks have offered loans for the installation of PV plants in the framework of the Special Program and there were many cases on which the loan covered $100 \%$ of the cost.

However, this very mechanism has also overheated the market. High feed-intariffs and dramatic decreases of PV costs since 2011 have led to a boom that the Electricity Market cannot sustain anymore. The EMO cannot raise the necessary funds for compensating the PV installations (hence there were time delays in payments of 5-8 months, 2-3 months to producers of Special Program), so this resulted to a deficit which for a part of it, the cause is the overestimated FiTs for PV and the underestimated development of PV installations.

The State in the last years has published several above mentioned ministerial decrees and a law which reduced the FiTs in existing and new installations. The first two attempts were with JMD 2317/10.08.2012 and JMD 1103/02.05.2013.

The highest reduction of FiTs was introduced on April 2014 with the L 4254/2014. This law changed the tariffs retrospectively for existing projects of 
Special Program with total capacity of approximately 318 MW (85\% of total installed capacity) which has been connected to the grid from July 2011 to the end of 2013. The mean tariff reduction was approximately $21 \%$. Moreover the annual price adjustment of $25 \%$ of the consumer price index of the previous year was repealed.

The Unions of the energy producers of the Special Program have started litigation against PPC since there are problems with the repayment of their loans.

In figure 4 there is the time evolution of the FiTs from the start of the Special Program until its end after legislative interventions from 2012-2014.

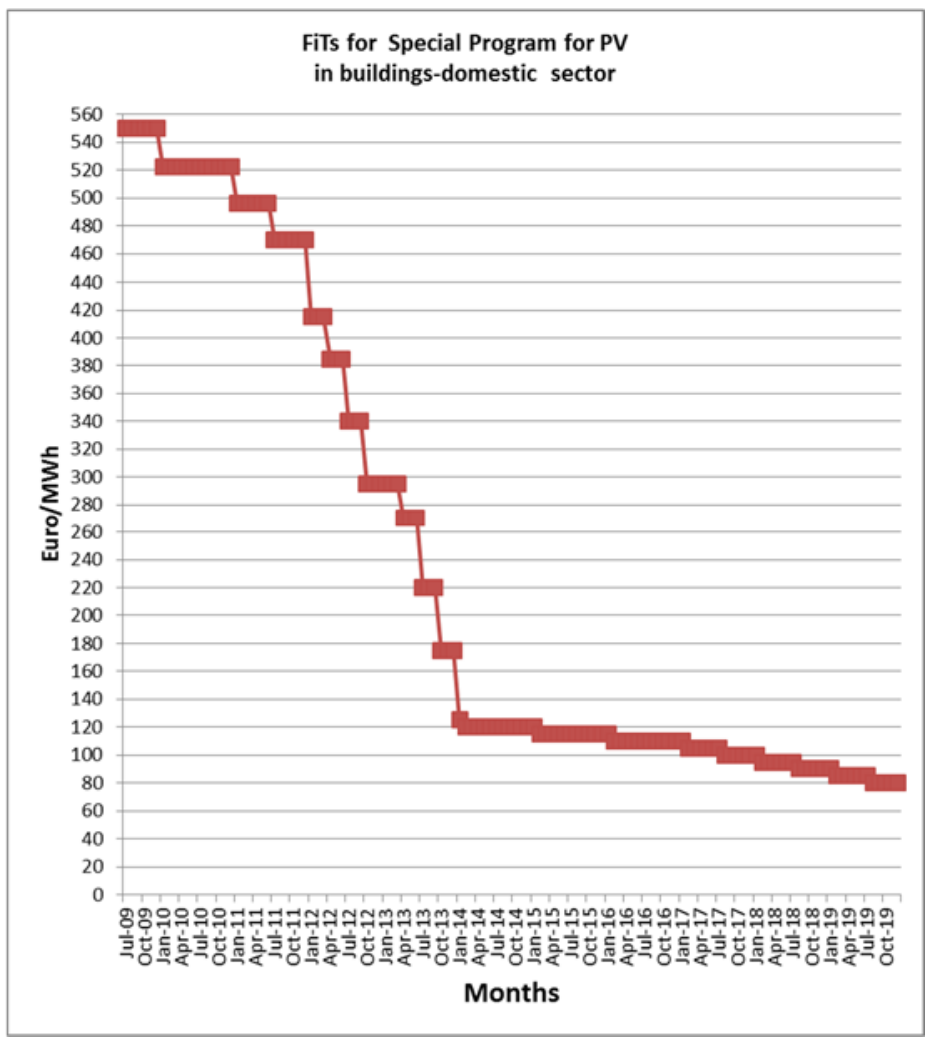

Figure 4: The FiTs for the Special Program for PV in residential sector.

\section{The PV market - specialization in buildings and domestic sector}

Greece ranks 5th worldwide with regard to per capita installed PV capacity. $€ 4.5$ billion was invested in PV in Greece during the last 5 years [4].

For a small country in an unprecedented financial crisis, this performance is indeed amazing. There is a very good reason for this: a brave support mechanism. 
Greece has been offering high feed-in-tariffs (FiTs) for PV since 2006. The cumulative installed PV capacity in the end of 2013 was $2.579 \mathrm{MW}$ of which 373 MW from the Special Program for residential systems $(<10 \mathrm{kWp})$.

In figure 5 it is presented the development of PV market development. The rapid growth started in 2010 when the installed capacity was increased by more than four times from the previous year. The cumulative installed capacity in 2013 was 55 times larger than 2009.

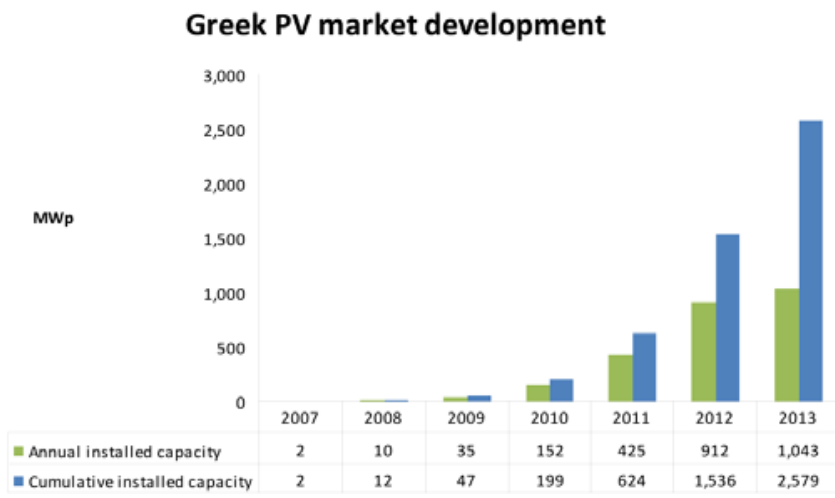

Figure 5: The development of the Greek PV market [4].

In figure 6 it is presented the categories of grid-connected systems per category in 2013. The percentage of residential grid-connected PV systems (Special Program) was about $14.4 \%$, the majority of the installations were commercialindustrial systems in mainland with a percentage of $80 \%$.

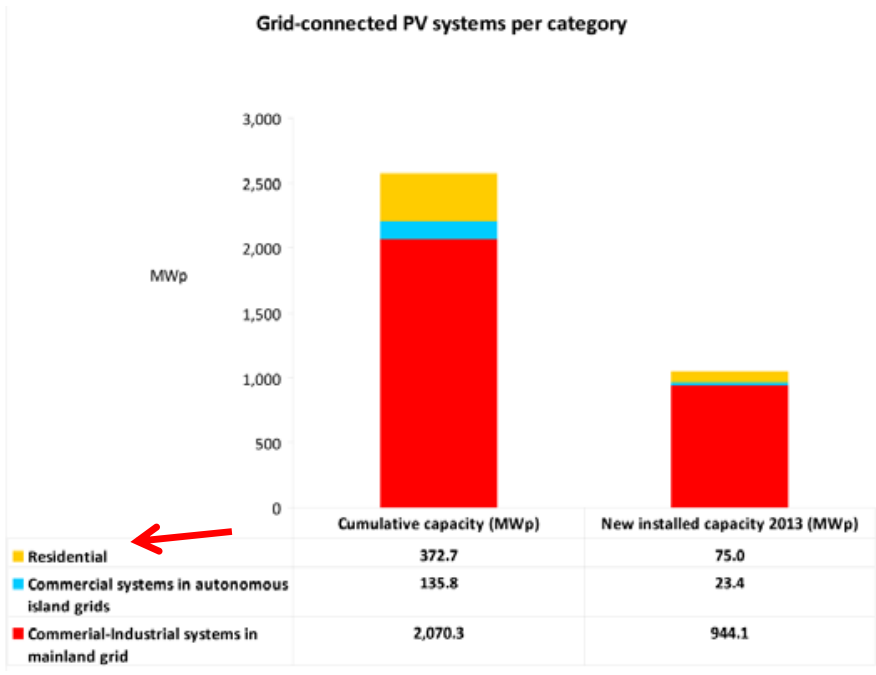

Figure 6: The grid-connected PV systems per category [4]. 
In figure 7 it is presented the cumulative installed capacity of grid-connected PV systems. It is clear that the noticeable penetration of PV installations of Special Program has started on March of 2011.

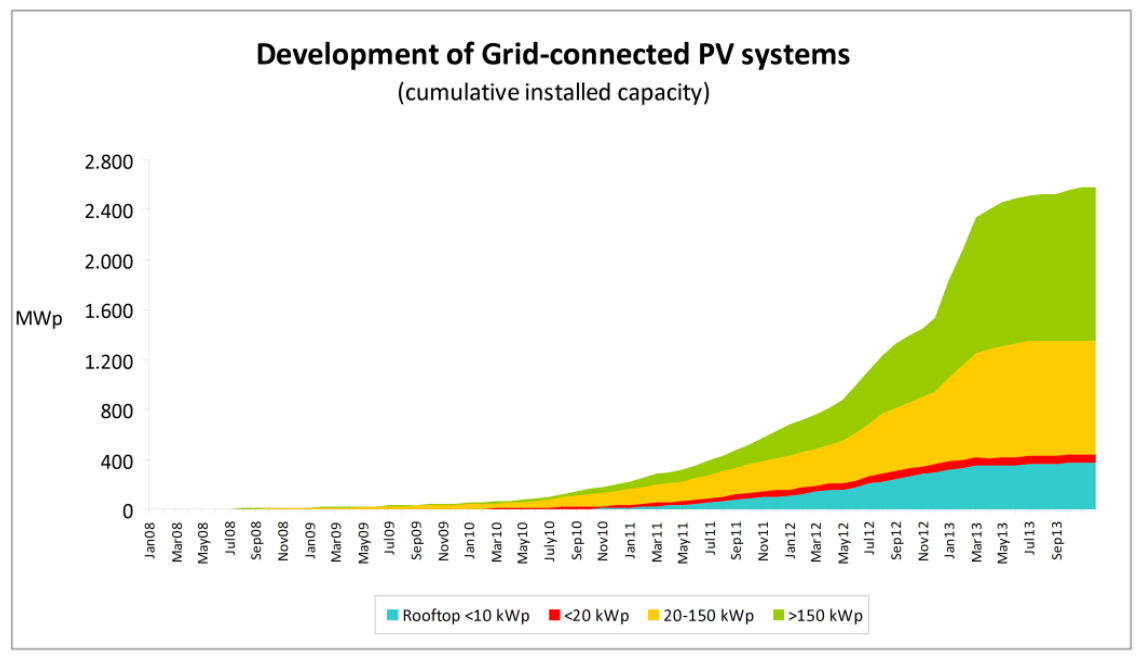

Figure 7: The development of the grid-connected PV systems [4].

\section{Environmental benefits of PV of the Special Program}

Every kilowatt hour generated by solar panels, and thus not from fossil fuels, implies avoiding release of approximately $850 \mathrm{gr}$ of carbon dioxide $\left(\mathrm{CO}_{2}\right)$ in atmosphere (based on the current energy mix in Greece and grid average losses) and other Greenhouse's gases [5]. It takes 1.3 acres of forest or approximately 65 trees to absorb this amount of $\mathrm{CO}_{2}$. To generate the same amount of electricity from 2.2 barrels of oil are needed each year.

The annual net capacity factor of PV installations of the Special Program is $15.7 \%[6,7]$.

So, in table 1 the succeeded avoided pollutants [8] due to the operation of PVs is presented.

Table 1: The avoided pollutants from the operation of PVs.

\begin{tabular}{|r|l|}
\hline $437.750,0$ & $\mathrm{tn} /$ year $\mathrm{CO}_{2}$ \\
\hline $7.982,5$ & $\mathrm{tn} /$ year $\mathrm{SO}_{2}$ \\
\hline 92.7 & $\mathrm{tn} /$ year $\mathrm{CO}$ \\
\hline 618.0 & $\mathrm{tn} /$ year NOx \\
\hline 25.8 & $\mathrm{tn} /$ year HC \\
\hline 412.0 & $\mathrm{tn} /$ year particles \\
\hline
\end{tabular}


The direct economic benefit of the Greek National Economy from the reduction of $\mathrm{CO}_{2}$ is 4.378 million Euros per year (estimated cost: 10 Euro per tn).

\section{$5 \quad$ Existing policies - barriers}

The crisis in the PV market in 2013-2014 gave, inter alia, rose critical comments with regard to the overall support mechanism policy of renewable energy sources (RES) followed in our country in recent years. This criticism has even sometimes questioned the need for the aid of photovoltaic and/or other renewables, but mainly focused on the way that was structured and implemented the supportive mechanism of electricity from RES.

Greece has chosen that the RES support mechanism (FiT) that turned the world more effective in the development of clean energy sources. It was wrong to provide guaranteed fixed price (feed-in-tariffs, FiT) in PVs, but it was wrong that the pace of decline has not followed the impairment rate cost of PVs. Rightly Greece was among the first countries that decided to support the PVs. Addressing climate change requires immediate meters, while the delayed action equivalent to no effect and leads to non-reversible destabilization of the global climate.

In 2009, the Special Development Program for PVs in buildings was initiated (high FiT with simplified licensing procedure), adopting a series of incentives for residential and small commercial consumers, giving them the opportunity to invest in small scale PVs. Already in 2011, the global PV market began to witness dramatic reductions in the cost of PV modules and hence also in total investment cost. It was soon apparent that this would lead to an opening gap between the rate that streamlines FiTs and the corresponding rate of the changing investment costs. This inevitably lead to overheating the market and that created a large deficit to the special account of the Electricity Market Operator (EMO) for RES Producers which resulted in time delays of several months in payments of producers.

In this situation, the State reacted spasmodically with the JMD 2317/ 10.08.2012 and JMD 1103/02.05.2013 with changes in tariffs without real evaluation of the cost trend of PV installations and the size of EMO's Special Account deficit. Thus, the period August 2012-May 2014 were led to disorientated market. The reason was the delay in adapting FiTs led to a deficit of the Special Account RES and ultimately retrospective reductions compensation in operating projects (L 4254/2014).

In figure 8 is presented the cumulative installed capacity of grid-connected PV systems of Special Program with the initial and final FiTs after legislative changes.

The reduced FiTs which have been defined with the JMD 1103/02.05.2013 for the period until the end of 2019 and the retrospective reductions of L 4254/2014, have created intimidation and insecurity to possible future investors of the Special Program. Hence, there is high reduction in installed capacity in 2014 (almost only 1MW new capacity) and small interest for new installations (e.g. a $10 \mathrm{kWp} \mathrm{PV}$ plant of the Special Program has simple payback period of 8-9 years).

The source of the problematic situation of the Greek electricity market is that many households are unable to pay their electricity bills due to the ongoing economic crisis and massive unemployment. This leads to a huge gap in the 
EMO's Special Account, which is also partly subsidized by electricity consumers. PPC's unpaid electricity bills at the end of 2014 reached the amount of $€ 2$ billion [9].

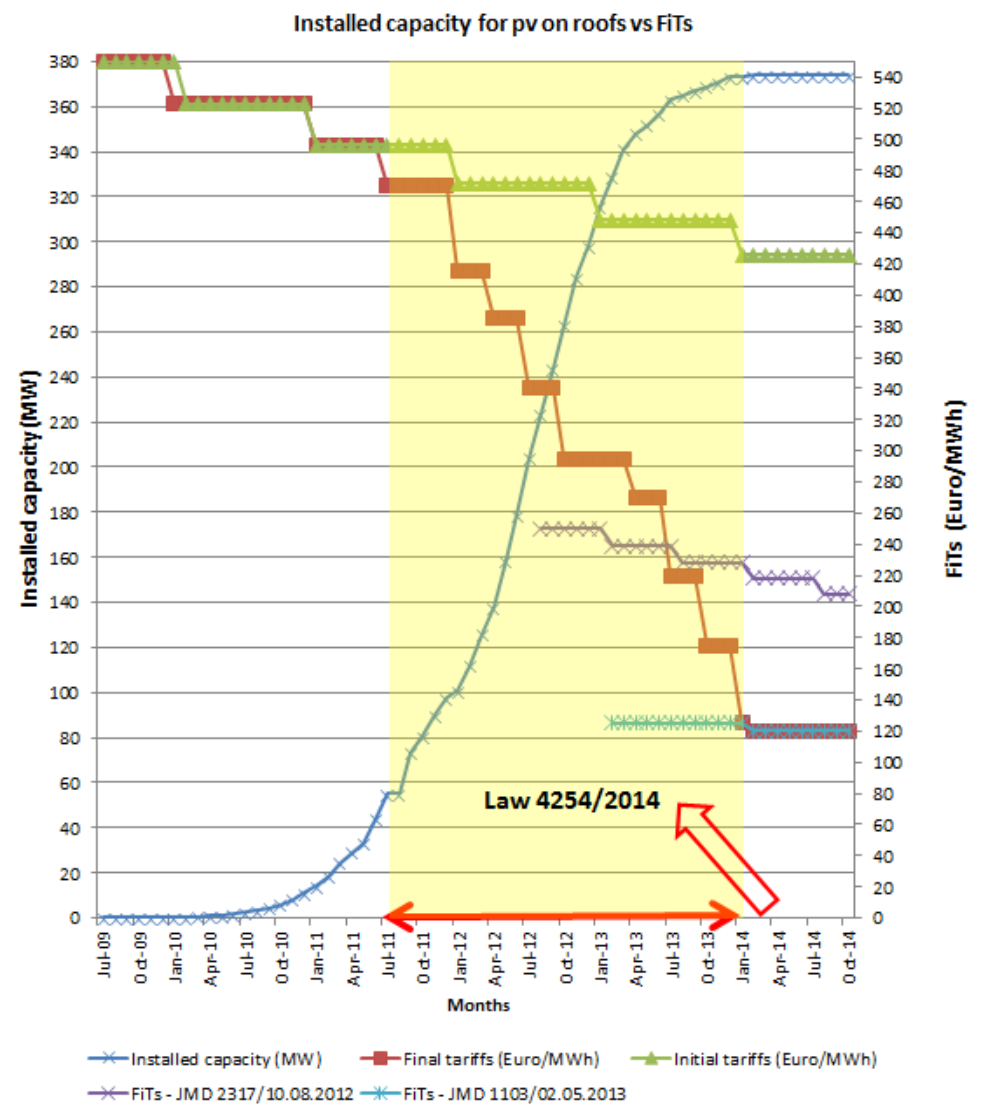

Figure 8: The cumulative installed capacity of grid-connected PV of Special Program with the initial and final FiTs after legislative changes.

In addition the lack of political and financial stability, the continuous delays in payments from EMO have frozen the PV market for a year and it is quite difficult to have a re-activation of this market sector until the aforementioned barriers are overcome.

\section{Conclusions - proposals}

The PV market in Greece and mainly the market of residential installations of Special Program are completely stagnant. The PV companies face serious feasibility problems and a lot of them have stopped their operations or have gone bankrupt, driving to an increase of unemployment. 
Also, due to the very limited new PV installations in last year, the taxes and the VAT are also reduced.

Moreover, the reduced FiTs in combination with the lack of investment security and stability (political and financial) the interest for new PV roofs in the frame of Special Program has disappeared. The EMO's Special Account deficit remains and delays in payments from PPC continue.

As a first step it is suggested to find solutions to the above mentioned issues and as a second step to apply the net-metering procedure.

Investments in PVs are a choice necessary to reduce carbon dioxide emissions and prevent dangerous climate change. The prevention can't wait until the reduction of the cost. Delayed action may prove not only more expensive for the society, but also ineffective. Unfortunately, we can't afford to postpone action to fight climate change. If we do not achieve significant changes in the energy mixture by the end of this decade, the majority of the scientific community agrees that this will have irreversible effects for the planet. Increasing global temperature must be held below $2^{\circ} \mathrm{C}$ compared with pre-industrial levels to avoid the worst impacts of climate change. To do this there should be a cap on the amount of coal that can be released into the atmosphere, that global emissions should peak the 2013-2020 period to begin to decline sharply thereafter.

PVs are proved in practice the most active energy technology in the last decade, the cost has been dramatically reduced and visible results have been achieved in reducing emissions. Rightly so Greece decided in 2009 to support this option. As rightly chose to make it through the feed-in-tariffs model, but the support mechanism was not able to monitor the dramatic reduction of investment cost and thus protect consumers.

\section{References}

[1] Statistics for the PV market in 2013, Hellenic Association of Photovoltaic companies (HELAPCO), http://helapco.gr/wp-content/uploads/pv-stats greece 2013 June14.pdf (in Greek)

[2] Monthly Report of Special Account for RES-November 2014, Electricity Market Operator (LAGIE S.A.),

http://www.lagie.gr/fileadmin/groups/EDSHE/MiniaiaDeltiaEL/2014_11_M iniaio_Deltio_EL_APESITHYA.pdf (in Greek)

[3] Frequent questions-answers on PV systems for the installation of PVs within the framework of the Special program for buildings, HEDNO SA,

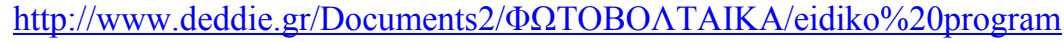
ma\%20steges/FAQ ON_PV_SYSTEMS 1.pdf

[4] Greek PV Market Statistics, Hellenic Association of Photovoltaic companies (HELAPCO), http://helapco.gr/wp-content/uploads/pv-stats_greece_eng2013.pdf (in Greek)

[5] Photovoltaics and environment, Hellenic Association of Photovoltaic companies (HELAPCO), http://helapco.gr/pdf/PV Environment.pdf (in Greek) 
[6] RES Brief report for RES - November 2014, Electricity Market Operator (LAGIE S.A.), http://www.lagie.gr/fileadmin/groups/EDRETH/RES/2014_11_GR_MONT HLY RES 01.pdf (in Greek)

[7] RES Brief report for RES - February 2013, Electricity Market Operator (LAGIE S.A.),

http://www.lagie.gr/fileadmin/groups/EDRETH/RES/2013 02 GR MONT HLY RES.pdf (in Greek)

[8] Greek Association of RES Electricity Producers, http://www.hellasres.gr/Greek/THEMATA/arthra/\%CA $\% \mathrm{CF} \% \mathrm{D} 3 \% \mathrm{D} 4 \% \mathrm{CF}$ $\% \mathrm{D} 3 \% \mathrm{C} 1 \% \mathrm{D} 0 \% \mathrm{C} 5 . \mathrm{doc}$ (in Greek)

[9] Energypress energy portal, http://www.energypress.gr/news/Nea-tameiakhasfyxia-gia-th-DEH-Badizoyn-pros-ta-2-dis.-eyrw-oi-aplhrwtoi-logariasmoi (in Greek) 